\title{
Atenolol may not modify anesthetic depth indica- tors in elderly patients - a second look at the data
} [L'aténolol ne modifierait pas les indicateurs de la profondeur de l'anesthésie chez les patients âgés - un réexamen des données]

Michael Zaugg MD DEAA, ${ }^{*}$ Thomas Tagliente MD PhD, $†$ Jeffrey H. Silverstein MD, $\ddagger$ Eliana Lucchinetti PhD $\mathfrak{S}$

Purpose: Decreased cardiac chronotropic response in elderly patients along with concomitant $ß$-blockade may suppress the autonomic responsiveness to surgical stimulation and subsequently obscure episodes of "light anesthesia".

Methods: We analyzed post hoc computerized data from our previous study evaluating the effects of perioperative atenolol administration. Bispectral index (BIS) and the performance of routine anesthetic depth indicators were analyzed in 45 patients undergoing abdominal surgery: Group I $(n=12)$, isoflurane/fentanyl/nitrous oxide in oxygen anesthesia; Group $\|(n=16)$, isoflurane/fentanyl/nitrous oxide in oxygen with $10 \mathrm{mg}$ atenolol intravenously prior to anesthesia; Group III ( $n=17)$, isoflurane/fentanyl/nitrous oxide in oxygen with a maximum end-tidal isoflurane concentration of 0.4 vol.\% and incremental doses of atenolol $(5 \mathrm{mg}$ intravenously stepwise). In all groups, blood pressure (BP) was maintained within $\pm 20 \%$ of preoperatively defined baseline BP and heart rate $(\mathrm{HR})$ between $50-80$ beats $\cdot \mathrm{min}^{-1}$. BP, HR, and end-tidal isoflurane were tested for their potential to predict BIS using a previously described statistical model $\left(\mathrm{P}_{\mathrm{K}}\right)$.

Results: Although Group III patients received on average 39.5\% less isoflurane compared with Group I patients $(P=0.006)$, and Groups II and III patients received on average 21\% less fentanyl compared with Group I patients $(P \leq 0.002)$, similar levels of intraoperative average BIS values (53-54) were obtained for all groups. Higher BIS values were reached at emergence in atenolol-treated patients. The performance of hemodynamic variables or end-tidal isoflurane to predict BIS was moderate even at critical intraoperative events, but unaffected by atenolol.

Conclusion: Atenolol reduces anesthetic requirements but may not modify anesthetic depth indicators in elderly patients.
Objectif : Chez les patients âgés, la diminution de la réponse cardiaque chronotropique, avec un B-blocage concomitant, peut supprimer la réactivité autonome à la stimulation chirurgicale et, par la suite, masquer les épisodes "d'anesthésie légère".

Méthode : Nous avons analysé les données informatisées de nos études précédentes pour évaluer les effets de l'administration périopératoire d'aténolol. L'index bispectral (B/S) et le rendement des indicateurs habituels de la profondeur de l'anesthésie ont été analysés chez 45 patients de chirurgie abdominale. Le groupe I $(n=12)$ comportait une anesthésie avec un mélange d'isoflurane/fentany/protoxyde d'azote dans de l'oxygène; le groupe II $(n=16)$, isoflurane/fentanyl/protoxyde d'azote dans de l'oxygène, avec l'administration intraveineuse de $10 \mathrm{mg}$ d'aténolol avant l'anesthésie; le groupe III ( $n=17)$, isoflurane/fentanyl/protoxyde d'azote dans de l'oxygène, dont une concentration téléexpiratoire maximale d'isoflurane de 0,4 vol.\%, et des doses progressives d'aténolol (palier de $5 \mathrm{mg}$ intraveineux). Dans tous les groupes, la tension artérielle (TA) a été maintenue à $\pm 20 \%$ de la mesure de base préopératoire et la fréquence cardiaque (FC) entre 50 et 80 battements $\mathrm{min}^{-1}$. La TA, la FC et l'isoflurane télé-expiratoire ont été évalués pour leur potentiel de prédiction du BIS en utilisant un modèle statistique précédemment décrit $\left(P_{K}\right)$.

Résultats : Même si les patients du groupe III ont reçu en moyenne 39,5 $\%$ moins d'isoflurane que ceux du groupe I $(P=0,006)$ et les patients des groupes II et III ont reçu en moyenne $21 \%$ moins de fentanyl que ceux du groupe I $(P \leq 0,002)$, les valeurs moyennes de BIS peropératoires ont été similaires (53-54) dans tous les groupes. Des valeurs de BIS plus élevées ont été atteintes chez les patients traités avec l'aténolol. La capacité des variables hémodynamiques ou de l'isoflurane télé-expiratoire à prédire le BIS a été modérée même pour des événements peropératoires critiques, mais elle n'a pas été modifiée par l'aténolol.

Conclusion : L'aténolol réduit les besoins anesthésiques, mais ne modifierait pas les indicateurs de la profondeur de l'anesthésie chez les patients âgés.

From the Institute of Anesthesiology, ${ }^{\star} \$$ University Hospital Zurich, Zurich, Switzerland; and the Department of Anesthesiology, $† \ddagger$ Mount Sinai School of Medicine, New York, USA.

Address correspondence to: Dr. Michael Zaugg, Institute of Anesthesiology, University Hospital, Zurich, Rämistrasse 100, CH-8091 Zurich, Switzerland. Phone: +41 125511 11; Fax: +41 125544 09; E-mail: michael.zaugg@ifa.usz.ch

This study was supported by the Grant 3200-063417.00 of the Swiss National Science Foundation and a Grant of the Swiss Heart Foundation.

Accepted for publication September 24, 2002.

Revision accepted February 12, 2003. 


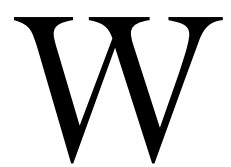

E recently reported the beneficial effects of $B$-adrenergic blockade in elderly patients undergoing noncardiac surgery. ${ }^{1}$ In this study, atenolol was shown to confer the advantage of administering less anesthetics, which resulted in a faster recovery from anesthesia. To evaluate whether the use of atenolol promotes "light anesthesia" ${ }^{2}$ and to investigate whether the ability to judge the adequacy of anesthetic depth is diminished by atenolol, we analyzed post hoc computerized data from a subgroup of the study patients with comparable surgical stimulation (abdominal surgery). Specifically, we examined the effects of atenolol on the performance of the routinely used anesthetic depth indicators, i.e., heart rate (HR), blood pressure (BP), and end-tidal anesthetic gas concentrations to predict depth of anesthesia, as indicated by the bispectral index (BIS), using a previously described statistical model. ${ }^{3}$

\section{Methods}

\section{Patients and study protocol}

From the 63 patients of the original study, ${ }^{1}$ the data from 45 patients, which fulfilled the following criteria were used for this analysis: 1) patients with abdominal surgery (comparable surgical stimuli); 2) patients with less than $1,000 \mathrm{~mL}$ of blood loss; 3 ) patients with less than $1 \%$ of missing electronically recorded data. In the original study, patients were randomly allocated to one of the following general anesthetic regimens: Group I: anesthetic technique without atenolol; Group II: anesthetic technique with preoperative administration of 10 $\mathrm{mg}$ atenolol intravenously $30 \mathrm{~min}$ prior to the start of anesthesia; Group III: anesthetic technique with intraoperative atenolol. In this group, maximum end-tidal isoflurane concentration was restricted to $0.4 \mathrm{vol} . \%$ and hemodynamics were controlled by stepwise $(5 \mathrm{mg})$ iv administration of atenolol. Exclusion criteria were pretreatment with $ß$-blockers and any contraindication for the study drug atenolol. ${ }^{1}$ For all patients, anesthesia was induced with 100 to $250 \mu \mathrm{g}$ fentanyl, propofol 1.7 $\mathrm{mg} \cdot \mathrm{kg}^{-1}$, and rocuronium $0.8 \mathrm{mg} \cdot \mathrm{kg}^{-1}$. Anesthetic maintenance was performed with isoflurane, $66 \%$ nitrous oxide in oxygen, a continuous infusion of fentanyl $\mathrm{l}$ to $2 \mu \mathrm{g} \cdot \mathrm{kg}^{-1} \cdot \mathrm{hr}^{-1}$, and rocuronium according to the surgical requirements. For all groups, BP was maintained within $20 \%$ of preoperatively defined baseline mean arterial blood pressure (MAP) and HR between 50 to 80 beats $\cdot \mathrm{min}^{-1}$. ${ }^{1}$

\section{Intraoperative monitoring and data management}

Data for HR, MAP, systolic arterial pressure (SAP), endtidal isoflurane concentrations, and BIS [A-1050 moni- toring system (software version 3.1) using Zipprep FpZF7 and FpZ-F8 electrodes, Aspect Medical Systems, Natick, MA, USA)] were automatically recorded from shortly before induction until eye opening. ${ }^{1}$ The raw electrocardiogram signals were band-pass filtered to 0.5 to $30 \mathrm{~Hz}$. The smoothening time of BIS was set at 30 $\mathrm{sec}$, and BIS was updated every five seconds. BIS data were blinded to the attending anesthesiologist. To eliminate artifacts, two-minute medians were computed for the recorded data. Absolute fractional changes between consecutive two-minute medians were calculated for all variables, as reported previously. ${ }^{1,4}$ The intraoperative period was defined from surgical incision until closure of the surgical wound. For this period, percent frequency distribution for intraoperative BIS values was calculated for the following ranges: $<40,40-50,50-60,60-70$, $70-80,>80$.

\section{Assessing the performance of routine anesthetic depth indicators}

Maximum BIS, HR, and SAP were determined for the predefined time points of intubation, incision, end of surgery, and extubation using the maximum values of data recorded \pm four minutes within the critical events. The performance to predict BIS was calculated for HR, MAP, SAP, their absolute fractional changes between two consecutive two-minute epochs, and end-tidal isoflurane concentration using the previously described statistical model of prediction probability $\left(\mathrm{P}_{\mathrm{K}}\right){ }^{3}$ Calculations for $\mathrm{P}_{\mathrm{K}}$ were performed with a custom spreadsheet macro PKMACRO (Prof. W.D. Smith, Sate University, Sacramento, CA, USA) using Excel (Microsoft Corporation, Redmond, WA, USA). $\mathrm{P}_{\mathrm{K}}$ for the times of intubation, incision, end of surgery, and extubation were calculated by using three two-minute medians immediately before and after the defined critical events.

\section{Statistical analysis}

Data are expressed as mean \pm SD, mean with $95 \%$ lower and upper confidence interval (for the prediction probability), or median (minimum, maximum), respectively, dependent upon the underlying data distribution. Oneway analysis of variance was used to test for intergroup difference. Bonferroni/Dunn procedure was used to correct for multiple comparisons. $P<0.05$ was considered statistically significant (StatView, Abacus Concepts, Inc., Berkeley, CA, USA).

\section{Results}

Of the 45 patients that met the selection criteria defined for the present subgroup analysis, 12 belonged to Group I, 16 to Group II, and 17 to 
TABLE I Administered drugs

\begin{tabular}{lllll}
\hline & Group I (control) & Group II (preoperative atenolol) & Group III (intraoperative atenolol) & $P^{*}$ \\
\hline Mean end-tidal isoflurane (\%) & $0.38 \pm 0.17$ & $0.40 \pm 0.20$ & $0.23 \pm 0.06$ & 0.0006 \\
Fentanyl $\left(\mathrm{mg} \cdot \mathrm{kg}^{-1} \cdot \mathrm{hr}^{-1}\right)$ & $1.9 \pm 0.5$ & $1.5 \pm 0.3$ & $1.5 \pm 0.4$ & 0.001 \\
Rocuronium $(\mathrm{mg} / \mathrm{case})$ & $122 \pm 53$ & $131 \pm 66$ & $115 \pm 58$ & 0.78 \\
Atenolol $(\mathrm{mg} / \mathrm{case})$ & 0 & 10 preop & $20(10,80)$ & \\
\hline
\end{tabular}

Data are mean \pm SD or median (minimum, maximum), $P^{\star}=$ ANOVA. Comparison of specific groups for isoflurane: I $v s$ II: $P=0.55, \mathrm{I} v s$ III: $P=0.006$, II $v s$ III: $P=0.003$, and for fentanyl: I $v s$ II: $P=0.001$, I $v s$ III: $P=0.002$, II $v s$ III: $P=0.95$. Preop $=$ preoperative. Reproduced with permission from Anesthesiology. ${ }^{1}$

TABLE II Performance of routine anesthetic depth indicators to predict bispectral index

\begin{tabular}{|c|c|c|c|c|c|}
\hline Variable predicting BIS & & $\begin{array}{l}P_{K} \text { Group I } \\
\text { (control) }\end{array}$ & $\begin{array}{l}P_{K} \text { Group II } \\
\text { (preoperative atenolol) }\end{array}$ & $\begin{array}{l}P_{K} \text { Group III } \\
\text { (intraoperative atenolol) }\end{array}$ & $P^{*}$ \\
\hline \multirow[t]{3}{*}{ End-tidal isoflurane } & overall & $0.38(0.36-0.42)$ & $0.41(0.36-0.46)$ & $0.39(0.33-0.44)$ & 0.67 \\
\hline & incision & $0.25(0.23-0.27)$ & $0.21(0.20-0.24)$ & $0.23(0.20-0.25)$ & 0.50 \\
\hline & end surgery & $0.32(0.29-0.35)$ & $0.34(0.32-0.36)$ & $0.32(0.30-0.34)$ & 0.82 \\
\hline \multirow[t]{5}{*}{ Heart rate } & overall & $0.49(0.41-0.57)$ & $0.48(0.42-0.54)$ & $0.59(0.55-0.64)$ & $0.007 \dagger$ \\
\hline & intubation & $0.59(0.57-0.61)$ & $0.62(0.59-0.63)$ & $0.58(0.56-0.61)$ & 0.66 \\
\hline & incision & $0.58(0.57-0.60)$ & $0.60(0.58-0.62)$ & $0.61(0.59-0.63)$ & 0.73 \\
\hline & end surgery & $0.59(0.57-0.62)$ & $0.62(0.60-0.64)$ & $0.72(0.71-0.76)$ & $0.003 \dagger$ \\
\hline & extubation & $0.65(0.63-0.67)$ & $0.67(0.64-0.69)$ & $0.75(0.73-0.78)$ & $0.008 \dagger$ \\
\hline \multirow[t]{5}{*}{ Change $\ddagger$ in heart rate } & overall & $0.48(0.46-0.51)$ & $0.49(0.47-0.52)$ & $0.52(0.50-0.54)$ & 0.11 \\
\hline & intubation & $0.59(0.57-0.60)$ & $0.57(0.56-0.59)$ & $0.59(0.57-0.62)$ & 0.77 \\
\hline & incision & $0.60(0.58-0.63)$ & $0.61(0.60-0.62)$ & $0.58(0.56-0.60)$ & 0.80 \\
\hline & end surgery & $0.64(0.62-0.66)$ & $0.62(0.60-0.64)$ & $0.72(0.70-0.74)$ & $0.001 \dagger$ \\
\hline & extubation & $0.62(0.61-0.63)$ & $0.63(0.61-0.65)$ & $0.79(0.77-0.81)$ & $0.001 \dagger$ \\
\hline \multirow[t]{5}{*}{ Systolic blood pressure } & overall & $0.44(0.38-0.50)$ & $0.47(0.43-0.51)$ & $0.47(0.43-0.50)$ & 0.46 \\
\hline & intubation & $0.56(0.54-0.58)$ & $0.58(0.56-0.57)$ & $0.56(0.54-0.58)$ & 0.60 \\
\hline & incision & $0.56(0.53-0.57)$ & $0.54(0.53-0.56)$ & $0.52(0.50-0.54)$ & 0.15 \\
\hline & end surgery & $0.52(0.51-0.55)$ & $0.55(0.52-0.56)$ & $0.53(0.51-0.55)$ & 0.67 \\
\hline & extubation & $0.52(0.51-0.54)$ & $0.51(0.50-0.53)$ & $0.55(0.52-0.56)$ & 0.12 \\
\hline \multirow[t]{5}{*}{ Change $\neq$ in systolic blood pressure } & overall & $0.48(0.46-0.51)$ & $0.49(0.47-0.52)$ & $0.52(0.50-0.54)$ & 0.11 \\
\hline & intubation & $0.58(0.56-0.60)$ & $0.56(0.54-0.58)$ & $0.60(0.58-0.61)$ & 0.53 \\
\hline & incision & $0.54(0.52-0.56)$ & $0.56(0.54-0.58)$ & $0.60(0.58-0.61)$ & 0.55 \\
\hline & end surgery & $0.55(0.53-0.57)$ & $0.53(0.52-0.55)$ & $0.53(0.51-0.54)$ & 0.57 \\
\hline & extubation & $0.52(0.50-0.54)$ & $0.54(0.52-0.56)$ & $0.57(0.55-0.57)$ & 0.34 \\
\hline
\end{tabular}

$\mathrm{P}_{\mathrm{K}}$ represents a measure of performance by which an indicator can predict correctly the rank order of an arbitrary pair of distinct observed anesthetic depths. An ideal anesthetic depth indicator is described by a monotonically decreasing or increasing function. The prediction probability $P_{K}$ has a value of 1 when the indicator predicts the observed anesthetic depth perfectly and the correlation is positive. $P_{K}$ has a value of 0 when the indicator predicts the observed anesthetic depth perfectly and the correlation is negative. $P_{K}$ has a value of 0.5 when the indicator predicts no better than chance. $P^{\star}=$ ANOVA for inter-group comparison; $\dagger=$ comparison between specific groups: heart rate overall, I $v s$ III: 0.016 , II $v s$ III: 0.004, heart rate end of surgery: I $v s$ III: 0.002, I $v s$ III: 0.001, heart rate extubation: II $v s$ III: 0.008 , I $p s$ III: 0.004; change in heart rate end of surgery: I $v s$ III: 0.001 , II $v s$ III: 0.001 , change in heart rate extubation: II $v s$ III: 0.001 , II $p s$ III: 0.001. ‡Changes between two consecutive two minute medians. As for SAP, no differences were detected for mean arterial pressure between groups. Data are mean with $95 \%$ lower and upper confidence interval.

Group III. There was no difference in patient characteristics between groups. ${ }^{1}$

\section{Administered amount of anesthetics and atenolol and intraoperative hemodynamics \\ The amount of administered anesthetics was different for the three groups (Table I). Group III patients received on an average $39.5 \%$ less isoflurane compared with Group I patients $(P=0.006)$, and Groups II and}

III patients received on an average $21 \%$ less fentanyl compared with Group I patients $(P \leq 0.002)$. Hemodynamic variables were similarly well controlled in all groups. ${ }^{1}$

\section{Anesthetic depth and recovery}

None of the patients experienced intraoperative awareness or recall, and the mean intraoperative BIS values were similar for all three groups $(53-54) .{ }^{1}$ There was 


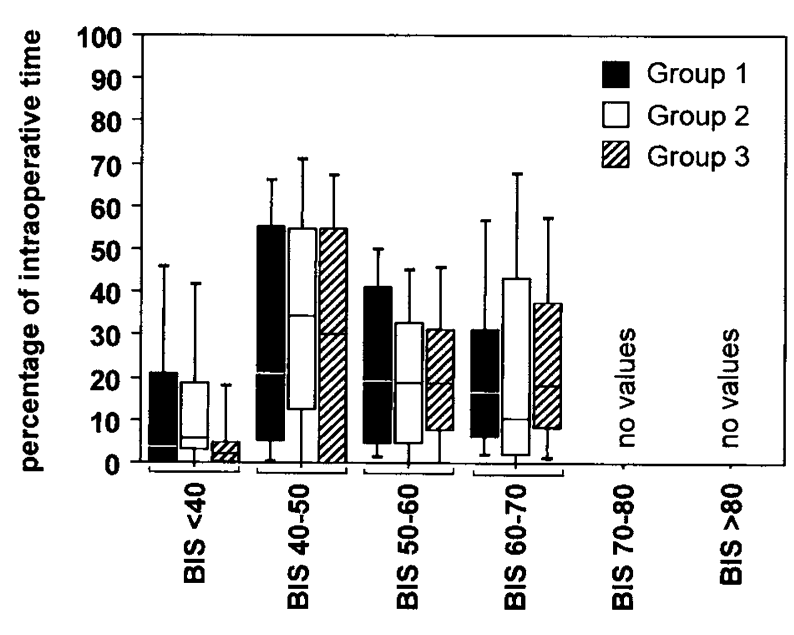

FIGURE 1 Percentages of intraoperative time for the indicated bispectral index (BIS) ranges are presented as box plots for the three anesthetic regimens (median, $25^{\text {th }}$ and $75^{\text {th }}$ percentile, $3^{\text {rd }}$ and $97^{\text {th }}$, respectively). There were no intraoperative BIS values higher than 70 in any of the three anesthetic regimens. Also, no significant differences between groups were observed for higher intraoperative BIS ranges.

no intraoperative increase in BIS values at higher BIS ranges in atenolol-treated patients (Figure 1 ). Conversely, higher BIS values were observed in both atenolol-treated groups at the end of surgery and at extubation (Figure 2). This is in accordance with our previously reported faster recovery from anesthesia in both ß-blocker groups. ${ }^{1}$

\section{Performance of routine anesthetic depth indicators}

Overall performance of all routine anesthetic depth indicators was in general poor, regardless of the anesthetic regimen or the presence or absence of $ß$-blockade (Table II). The performance of the indicators measured at critical time points, i.e., at intubation, at incision, at the end of surgery, and at extubation was markedly higher, but still not satisfactory (ideally $\mathrm{P}_{\mathrm{K}}>$ 80 or $\left.\mathrm{P}_{\mathrm{K}}<20\right)$. In all study groups, end-tidal isoflurane concentrations could predict BIS best. Unexpectedly, HR as well as the change in HR could predict intraoperative BIS significantly better under higher doses of atenolol (Table II).

\section{Discussion}

In this study, we evaluated the effect of perioperative atenolol on anesthetic depth as indicated by BIS in patients undergoing abdominal surgery. ${ }^{1}$ Atenolol significantly decreased anesthetic requirements, but did

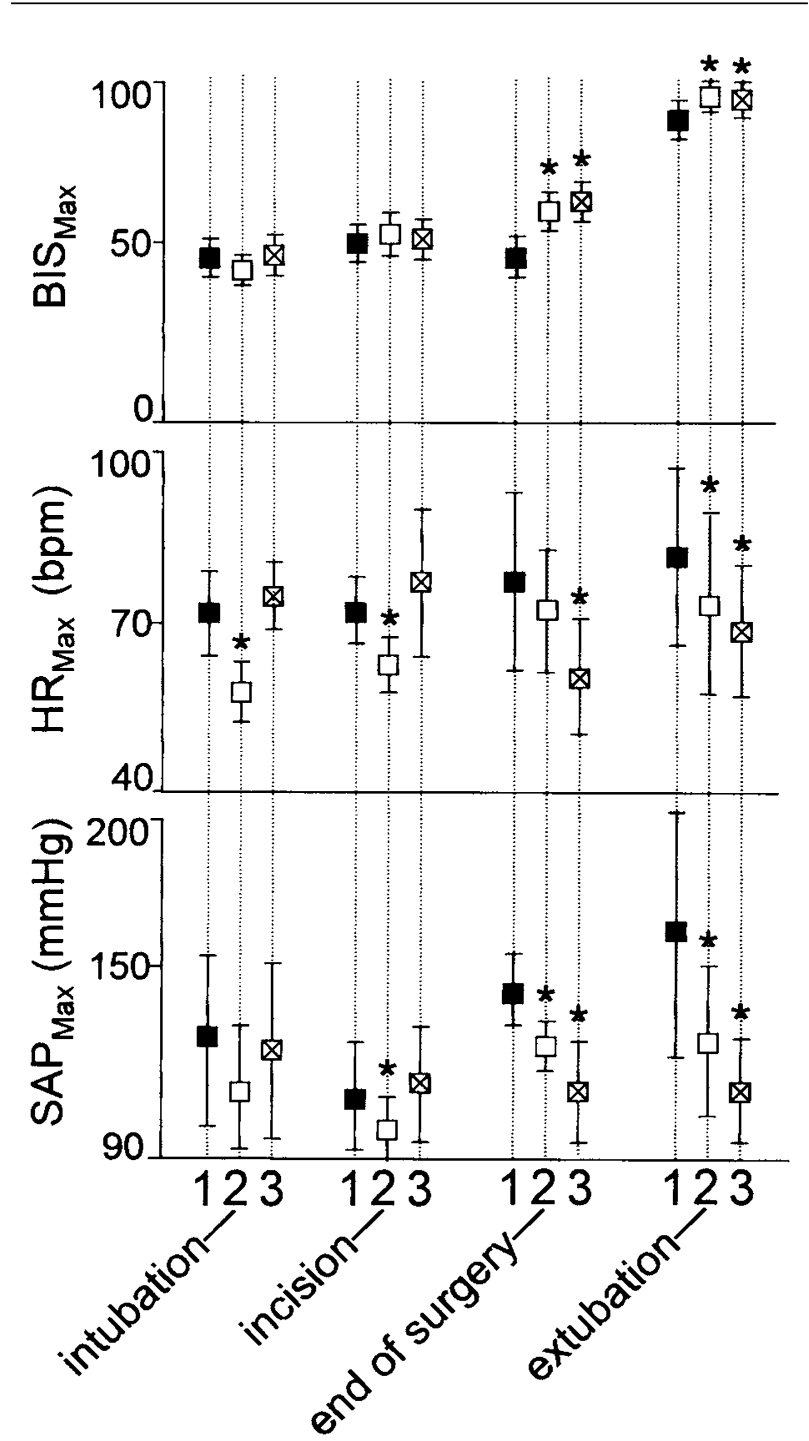

FIGURE 2 Bispectral index (BIS) and hemodynamics at specific time points. There was no increase in peak BIS at intubation or incision in patients treated with atenolol. Conversely, higher BIS values were observed in both atenolol-treated groups (Groups I and II) at the end of surgery and at extubation. Heart rate and blood pressure were better controlled in both B-blocker groups, particularly at the time of extubation. BIS $_{\mathrm{MAX}}=$ maximum bispectral index; $\mathrm{HR}_{\mathrm{MAX}}=$ maximum heart rate $\left(\right.$ beats $\left.\cdot \mathrm{min}^{-1}\right)$; and $\mathrm{SAP}_{\mathrm{MAX}}$ $=$ maximum systolic arterial pressure $(\mathrm{mmHg})$ at the indicated time points. *Significantly different compared to Group I (control). Data are mean \pm SD. 1 = Group I; 2 = Group II; 3 = Group III.

not appear to alter the level of hypnosis. This is consistent with previous studies where esmolol decreased anesthetic requirements for skin incision, ,,6 and directly promoted electroencephalographic burst suppression during anesthesia. ${ }^{7}$ Conversely, a significantly 
faster recovery from anesthesia was observed in our $\beta$ blocker-treated patients. ${ }^{1}$ Titration of anesthetics to $\mathrm{HR}$ and BP without $\mathrm{B}$-blockade may lead to prolonged recovery from anesthesia due to administration of higher doses of anesthetics (MAC-BAR > MACawake). ${ }^{8}$ Our post hoc analysis also evaluated the impact of B-blockade on the performance of routine anesthetic depth indicators using the previously established model of prediction probability $\mathrm{P}_{\mathrm{K}} \cdot{ }^{3}$ The results of these analyses indicate that routinely used hemodynamic variables do not reliably predict BIS, regardless of the presence or absence of $\beta$-blockade. Poor prediction of the hypnotic state by hemodynamic variables was recently reported by Struys et al. ${ }^{9}$ Interestingly, we observed a better performance of HR to predict BIS in the presence of higher doses of atenolol. Although end-tidal anesthetic concentration could predict BIS better than any hemodynamic variable, this correlation was weak, but unaffected by ß-blockade.

In summary, atenolol reduces anesthetic requirements but may not modify anesthetic depth indicators in elderly patients.

\section{Acknowledgement}

The authors are indebted to Prof. W.D. Smith for providing the PKMACRO software used in this study.

\section{References}

1 Zaugg M, Tagliente T, Lucchinetti E, et al. Beneficial effects from $B$-adrenergic blockade in elderly patients undergoing noncardiac surgery. Anesthesiology 1999; 91: 1674-86.

2 Hameroff SR, Polson JS, Watt RC. Monitoring anesthetic depth. In: Blitt CD, Hines RL (Eds.). Monitoring in Anesthesia and Critical Care Medicine, 3rd ed. New York: Churchill Livingstone; 1995: 491-507.

3 Smith WD, Dutton RC, Smith NT. Measuring the performance of anesthetic depth indicators.

Anesthesiology 1996; 84: 38-51.

4 Reich DL, Osinski TK, Bodian C, et al. An algorithm for assessing intraoperative mean arterial pressure lability. Anesthesiology 1997; 87: 156-61.

5 Johansen JW, Schneider G, Windsor AM, Sebel PS. Esmolol potentiates reduction of minimum alveolar isoflurane concentration by alfentanil. Anesth Analg 1998; 87: 671-6.

6 Johansen JW, Flaishon R, Sebel PS. Esmolol reduces anesthetic requirement for skin incision during propofol/nitrous oxide/morphine anesthesia. Anesthesiology 1997; 86: 364-71.

7 Johansen JW. Esmolol promotes electroencephalographic burst suppression during propofol/alfentanil anesthesia. Anesth Analg 2001; 93: 1526-31.
8 Zaugg M, Schaub MC, Pasch T, Spahn DR. Modulation of $\beta$-adrenergic receptor subtype activities in perioperative medicine: mechanisms and sites of action. $\mathrm{Br} \mathrm{J}$ Anaesth 2002; 88: 101-23.

9 Struys MM, Jensen EW, Smith WD, et al. Performance of the ARX-derived auditory evoked potential index as an indicator of anesthetic depth. A comparison with bispectral index and hemodynamic measures during propofol administration. Anesthesiology 2002; 96: 803-16. 